REVISTA DE DERECHO UNED, NÚM. 11, 2012

\title{
MARCO COMPARADO DE LA LIBERTAD RELIGIOSA EN EUROPA ${ }^{1}$
}

\section{A COMPARATIVE STUDY OF THE RELIGIOUS FREEDOM LAWS OF EUROPE}

\author{
ANA FERnÁNDEZ-Coronado GonZÁLEZ \\ Catedrática de Derecho Eclesiástico del Estado \\ Universidad Complutense de Madrid \\ afercor@der.ucm.es
}

Resumen: La consolidación de la Unión Europea como una unidad política y su estructuración jurídica ha planteado una seria de cuestiones importantes en los diversos campos del derecho. Este trabajo de investigación se centra en uno de esos ámbitos: el del Derecho de Libertad de Conciencia como objeto del Derecho Eclesiástico del Estado. La relevancia del tema reside en la existencia de una doble regulación jurídica de este derecho, no siempre coincidente: la de los Estados miembros de la Unión, que consideran esta cuestion como parte de su identidad, y la del Derecho Comunitario como derecho supranacional.

Con este punto de partida, la posibilidad de lograr una armonización legislativa en la materia plantea indudables dificultades, sobre todo en la dimensión colectiva del Derecho de Libertad de Conciencia, pues el aspecto individual no plantea mayores problemas. La razón de esta dificultad se encuentra en el enorme peso de las religiones tradicionales en los distintos Estados, hecho que condiciona a menudo la legislación de los mismos, en perjuicio de la plena realización de esa libertad, sobre todo para las minorías religiosas,

${ }^{1}$ Trabajo realizado en el marco del Proyecto de Investigación I+D: Presente y futuro de la diversidad ideológica y religiosa en España. Propuestas para la reforma de la Ley Orgánica de Libertad Religiosa (DER 2010-18748). 
establecidas como consecuencia del pluralismo cultural fruto de la inmigración.

El análisis de estos dos espacios jurídicos, Derecho de los Estados y Derecho Comunitario, permitirá valorar el alcance de una posible armonización legislativa con proyección de futuro.

Palabras clave: Libertad de Conciencia, Derecho Eclesiástico del Estado, Confesiones Religiosas, Derecho Comunitario, armonización legislativa.

Abstract: The consolidation of the European Union as a political entity and the articulation of a European Community Law raise certain relevant questions in different fields of law. This research focuses in a particular sphere: the freedom of conscience as object of Law and religion. The relevance of this issue is due to the existence of a double juridical regulation -not necessarily coincident- of the freedom of conscience: the European Union Member States regulations, which consider this subject as part of their respective identities; and the European Community Law regulation.

As a result, the legislative harmonization of this subject faces important difficulties, especially as far as the collective dimension of the Right to freedom of conscience is concerned -the individual dimension does not raise major problems-. The referred difficulty is due to the enormous weight of the traditional and historic religions in the different States, which determine in many occasions their legislations. This has a detrimental effect on the secularity of the States, as well as on the rights of minority religious groups, which are the result, to a large extent, of the cultural pluralism arising from immigration.

The analysis of these two juridical spaces -State laws and European Community Law- will allow us to assess the implications of a possible legislative harmonization in the future.

Keywords: Freedom of conscience, Law and religion, religious groups, European Community Law, legislative harmonization.

Recepción original: 30/07/2012

Aceptación original: 31/07/2012

Sumario: I. Introducción; II. La situación del Derecho de libertad religiosa en la Unión Europea; II.1. Ámbito de los Estados miembros; II.1.A. Planteamiento previo; II.1.B. Las democracias europeas tradicionales; II.1.B.a) Modelos de Iglesia de Estado; II.1.B.b) Modelos de Estado laico; II.1.C. Los Estados de la am- 
pliación europea de 2004-2006; II.1.D. Estados Europeos no comunitarios; II.2. Ámbito del Derecho Comunitario; III. Convergencia jurídica del Derecho de los Estados y el Derecho Comunitario en materia de libertad de conciencia.

\section{INTRODUCCIÓN}

Cuando hablamos de Europa hoy en día, se suele utilizar este término como sinónimo de Unión Europea. Sin embargo, aunque es cierto que la gran mayoría de los Estados Europeos están integrados en la Unión o participan en alguna de sus estructuras ${ }^{2}$, hay otros que están fuera de la Europa común.

No obstante, la importancia e influencia de la Unión Europea en todos los órdenes hace necesario que el análisis comparado de la libertad religiosa en Europa, objeto de este estudio, se deba de centrar especialmente en esta estructura supranacional. Este será, entonces, el punto de partida obligado, sin perjuicio de aludir, también, a la situación de la libertad religiosa en los Estados ajenos a la Unión que ofrecen un mayor interés en la actualidad, más aún cuando en alguno de ellos se plantean problemas importantes en relación a este derecho fundamental.

La configuración de la UE como una unidad socio-política, más allá de la mera unión económica ${ }^{3}$, planteó la posibilidad de estructurar jurídicamente un Derecho común europeo en materia de libertad de Conciencia. El Tratado de Maastricht (artículo F. 2) recogía ya el compromiso de la Unión Europea de respetar los derechos fundamentales, tomando como parámetros de esta protección el Convenio Europeo de Derechos Humanos de 1950 y las tradiciones constitucionales comunes a los Estados miembros. La Carta de Derechos Fundamentales de la Unión Europea del año 20004 había abierto, por su parte, importantes expectativas al respecto, pues, aunque careció de valor jurídico hasta el Tratado de Lisboa de diciembre de 2009, fue el primer texto en materia de derechos fundamentales

\footnotetext{
${ }^{2}$ Por ejemplo el Espacio Schengen sobre libre circulación del que forman parte Noruega, Islandia, Suiza y Liechtenstein.

${ }^{3}$ Con el Tratado de Maastricht de 1992 la unión económica y monetaria experimentó un avance definitivo y se inició el paso hacia una unión política.

${ }^{4}$ La Carta fue aprobada en la Conferencia Intergubernamental de Niza de diciembre del año 2000. [Diario Oficial de las Comunidades Europeas (DOCE) de 18 de diciembre de 2000 (2000/C364/01)].
} 
en el ámbito de la Unión y estableció un marco general en esta materia de indudable influencia en los Estados miembros.

Sin embargo, la pretensión de alcanzar un derecho común en materia de libertad de conciencia, parece hoy cada vez más lejana, pues la propia consolidación de la Unión Europea como ente socio-político supranacional, carece por el momento de la solidez necesaria para lograr este cometido. Basta con echar una ojeada a los problemas que se están produciendo en el campo económico, que en principio parecía el más cohesionado, para darse cuenta de las dificultades que ofrece un tema como el derecho de libertad religiosa, donde los Estados hacen valer la obligación del respeto al principio de identidad de cada uno de ellos, garantizado por el propio Tratado de la Unión.

No hay que olvidar, además, que la plena realización de este derecho, como derecho a formar unas creencias en el fuero interno, a manifestarlas externamente y a comportarse de acuerdo a ellas, en terminología de Llamazares (2011, I: 21-23), exige tener en cuenta no sólo el aspecto individual de esta libertad, sino también su dimensión colectiva, ya que los individuos suelen necesitar integrarse en grupos, por ejemplo, confesiones religiosas o asociaciones filosóficas, para que este derecho sea plenamente efectivo. Y es, precisamente, en la relación de los Estados con estos colectivos donde surgen, según se verá, las principales dificultades.

El tema se complica, también, debido a su regulación jurídica en dos niveles normativos diferentes no siempre coincidentes: el nivel de los Estados miembros, y el nivel de la Unión Europea, como entidad supranacional que aglutina a éstos.

En consecuencia, he distinguido dos apartados en el análisis de esta parte del estudio. En primer lugar, la situación de la libertad religiosa en los distintos Estados de la Unión, donde incluiré una referencia a otros Estados no integrados pero con especial relevancia, bien por su influencia en Europa o por su próxima adhesión. En segundo, la posición del Derecho Comunitario sobre el tema, que se ha ido perfilando a lo largo de las sucesivas reformas de los Tratados.

Del resultado del análisis de estos dos espacios, se podrá deducir un tercer apartado de carácter común: el grado de convergencia jurídica posible sobre el derecho de la libertad de 
conciencia en el ámbito de la Unión Europea con una proyección de futuro.

\section{LA SITUACIÓN DEL DERECHO DE LIBERTAD RELIGIOSA EN LA UNIÓN EUROPEA}

\section{II.1. Ámbito de los Estados miembros}

\section{II.1A. Planteamiento previo}

Los modelos de relación que coexisten en los países miembros de la Unión son, bastante diversos. Sin embargo, todos ellos tienen su raíz común en la tradición cristiana. El cristianismo ha sido durante siglos el fundamento cultural y ético de la sociedad europea y una de las bases esenciales para la configuración de cada Estado, aunque tampoco se puede olvidar la aportación del judaísmo y del islamismo, tanto desde una perspectiva histórica, como la de este último en la realidad social actual, debido a la fuerte inmigración en Europa de países de origen islámico ${ }^{5}$.

Este cristianismo presente en la historia religiosa de Europa se convulsiona, como es sabido, con la Reforma Protestante que quiebra la unidad religiosa del cristianismo católico e introduce un sistema de relación estricto de Iglesia de Estado, en el que los monarcas de los Estados en los que triunfó la Reforma, adquieren la competencia jurídica sobre la materia religiosa, por voluntad de los propios reformadores. Este modelo triunfó plenamente en algunos países, fue rechazado con fuerza en otros, que mantuvieron el catolicismo tradicional, y coexistió en condiciones equiparables con el catolicismo en algunos más.

La Ilustración, por su parte, marcó el inicio de la secularización de la libertad religiosa en el sentido de libertad no solo para tener unas u otras creencias religiosas, sino también para no tener ninguna. Esta secularización influyó en los modelos de relación de los Estados con las confesiones, dando lugar en algunos casos al establecimiento de Estados con fuertes tendencias hacia una laicidad estricta, como fue el caso de Francia.

${ }^{5}$ En 2010 había más de 44 millones de musulmanes en Europa. Pew Research Center's Forum on Religion Public Life. The Future on the Global Muslim Population, January 2011. 
De este modo, el derecho de libertad religiosa se fue reconociendo, paulatinamente, como un derecho civil. El derecho de igualdad, por el contrario, no logró el mismo desarrollo, debido a la pervivencia de status jurídicos privilegiados para las religiones tradicionales en muchos Estados, con la consiguiente discriminación negativa para los grupos minoritarios. Esta realidad, además, repercutió en el propio derecho de libertad de conciencia a nivel colectivo, impidiendo su plenitud.

La idea de Estado laico, como Estado neutral respecto de individuos y grupos y como Estado separado de las iglesias y sus dogmas, se empieza a configurar a lo largo de los siglos XIX y XX como el único sistema donde se puede realizar plenamente la libertad de conciencia. Esta idea cuaja definitivamente en las democracias occidentales después de la segunda guerra mundial, quizá como reacción a las experiencias fascistas, con las Declaraciones sobre Derechos Humanos realizadas a nivel universal y europeo ${ }^{6}$. No obstante, hasta el momento no ha logrado su pleno desarrollo.

A la hora de abordar el análisis de esta primera parte, he optado por distinguir dos grupos diferentes de Estados. El de los quince países que integraron la Unión Europea desde el momento en que se produjo la unión política a partir del Tratado de Maastricht. Y el de los doce que se incorporaron más tarde y que pertenecían en su mayoría a los llamados Países del Este, de influencia soviética. La razón de esta división estriba en la importante diferencia entre un grupo y otro en relación al respeto y promoción del derecho de libertad de conciencia y los derechos fundamentales en general ${ }^{7}$.

\section{II.1.B. Las democracias Europeas tradicionales}

El primer grupo coincide con las democracias europeas tradicionales, donde incluyo a España, Portugal, Grecia e Italia. Está última, porque, aunque fue confesional hasta 1984, su vieja Constitución de 1948 es plenamente democrática, con libertad religiosa y pleno respeto de los derechos fundamentales de la persona. España y Portugal porque, aunque fueron Estados dictatoriales y confesionales

${ }^{6}$ Declaración Universal de Derechos Humanos de 10 de diciembre de 1948, Pactos Internacionales de Derechos Civiles y Políticos y de Derechos Económicos, Sociales y Culturales de 16 de diciembre de 1966 y Convenio Europeo para la protección de los Derechos Humanos y las Libertades Fundamentales de 4 de noviembre de 1950.

${ }^{7}$ La legislación de los Estados Europeos, se puede consultar en la Crónica Legislativa de la revista Laicidad y Libertades. Escritos Jurídicos, números 1 a 11. 
hasta mediados de los años setenta del pasado siglo, son Estados cuyo objetivo esencial es la dignidad humana y el libre desarrollo de los derechos inherentes a ella, lo que se ha traducido en una evidente secularización de sus sociedades y un importante elenco normativo en materia de derechos y libertades fundamentales.

Grecia, por el contrario, como veremos, es la única de los quince que plantea más problemas.

En este primer grupo se puede hablar como marco general de modelos de Iglesia de Estado y modelos de Estado Laico. En ambos casos, según veremos, con importantes matizaciones. (ver Fernández-Coronado 2002: 67-94, y bibliografía de la nota 9).

\section{II.1.B.a) Modelos de Iglesia de Estado}

Responden a un sistema de iglesia de Estado: Inglaterra, Suecia, Finlandia, Dinamarca y, con muchas cautelas, Grecia. El modelo de Iglesia de Estado se caracteriza por las estrechas y amplias relaciones entre la autoridad del Estado y la vida de una iglesia concreta. El Estado considera a esa iglesia como propia y le concede una posición privilegiada. Pero esa iglesia está sometida al Estado, que legislara todo el contenido de su derecho, salvo los aspectos meramente espirituales. En definitiva, no hay separación, ni tampoco neutralidad del Estado.

Sin embargo, estos Estados difieren entre sí respecto de la pureza del modelo adoptado. Los países nórdicos, al ser Estados sociales y democráticos de Derecho más evolucionados, favorecen en sus Constituciones la tutela de los derechos inherentes a la dignidad humana. Ello ha producido un amplio desarrollo del pluralismo, que ha tenido como consecuencia un pleno reconocimiento del derecho de libertad de conciencia en el aspecto individual. Esta realidad ha llevado a una clara tendencia de futuro hacia la autonomía jurídica de las iglesias nacionales con respecto del Estado.

Así, la separación ya se ha producido en Suecia y Finlandia en sendas reformas constitucionales en vigor desde el año 2000, que han supuesto un freno a buena parte de los privilegios de los que gozaba la iglesia nacional, la evangélica luterana en ambos países, así como la iglesia ortodoxa en Finlandia, asimilada a la iglesia nacional. (Church of Sweden Act (1998:1591), Act on religious communities (1998:1593) (ver Murillo, Pardo, Rodríguez 2001: 559-598). 
En Dinamarca, por el contrario, no hay separación ${ }^{8}$. La iglesia nacional es un organismo estatal de la administración central sometido al Parlamento, que regula su derecho.

Finalmente, y aunque no forman parte de la Unión Europea, Noruega e Islandia están, también, en proceso de separación. En Islandia desde una Ley de 2007 el nombramiento de ministros de culto ya no lo hace el Estado, y en Noruega se ha constituido una Comisión para la autonomía jurídica de la iglesia nacional, que estima la separación para 2012, mediante la modificación del artículo 2 de la Constitución. La iglesia evangélica luterana dejará de ser oficial pasará a ser iglesia tradicional, en concreto, una iglesia popular estatutaria. (Murillo et al 2008: 187, 188). En ambos Estados se permite, además, a la iglesia luterana la celebración religiosa del matrimonio entre personas del mismo sexo, admitido en los dos países, al igual que en Suecia9.

Semejante a los países nórdicos es el caso de Inglaterra, donde la Reina es la gobernadora suprema de la iglesia anglicana, y el Parlamento organiza la iglesia y controla la doctrina y el culto.

Existe, también, plena libertad de conciencia individual, aunque, al carecer de una Constitución escrita, no hay garantías formales para la libertad religiosa. Sin embargo, en el año 2000 Inglaterra incorporó el Convenio Europeo de los Derechos Humanos de 1950 a su legislación nacional, lo que ya supone una importante garantía. Además, el poder civil siempre ha reconocido el derecho de toda persona a seguir los dictados de su conciencia en conformidad con sus creencias.

En el ámbito colectivo la iglesia anglicana tiene una situación privilegiada, especialmente en el ámbito jurídico. El derecho de esta iglesia es una parte del Derecho inglés. Sin embargo, a diferencia de las demás Iglesias de Estado, la iglesia anglicana se autofinancia con cargo a un fondo histórico [ver Mac Clean (1996: 311-327)]. Todas las demás confesiones tienen la posición jurídica de cualquier asociación, y carecen de una normativa que el Estado reconozca como Derecho eclesiástico.

En los últimos años también se está produciendo en el Reino Unido una separación progresiva. El Sínodo General, máximo órgano colegiado de la iglesia anglicana va aumentando su poder poco a

${ }^{8}$ Artículos 4 y 66 de la Constitución de 1953.

${ }^{9}$ Ley noruega de 17 de junio de 2008, Ley de la República de Islandia de 11 de junio de 2010, Ley sueca de 21 de enero de 2009. 
poco en detrimento del Parlamento. De otro lado, en Gales e Irlanda del Norte las iglesias anglicanas ya se han separado del Estado e incluso en Escocia la iglesia nacional presbiteriana es autónoma (Barbier 1995: 173).

El caso de Grecia es mucho más problemático. La Constitución griega realiza, teóricamente, una protección plena de los derechos fundamentales en su contenido individual, aunque en la práctica existen algunas limitaciones, como la prohibición del proselitismo.

En el aspecto colectivo, establece como religión dominante, la ortodoxa griega, pero garantiza su autonomía interna, salvo la organización de su nivel superior (patriarcado). No responde entonces estrictamente a la categoría de Iglesia de Estado, sino a una iglesia con predominio nacional con una situación jurídica privilegiada otorgada por el Estado ${ }^{10}$.

La iglesia ortodoxa tiene la categoría de persona jurídica de derecho público, y las demás confesiones la de personas jurídicas privadas y el reconocimiento de nuevas iglesias exige un informe previo de la iglesia ortodoxa como iglesia dominante.

Grecia es, sin duda, de entre estos países el que plantea más problemas respecto a su camino hacia la laicidad. No obstante, a través de su adhesión al Convenio Europeo de los Derechos Humanos de 1950, obligatoria para los Estados miembros de la Unión Europea, se está viendo obligada a modificar su legislación en determinados contenidos. El Estado ha sido condenado por el Tribunal Europeo de los Derechos Humanos en varios casos sobre proselitismo ${ }^{11}$.

Como conclusión a lo analizado hasta aquí, se puede señalar que en los modelos de Iglesia de Estado de la Unión Europea el derecho de libertad religiosa individual está plenamente garantizado, mediante la tutela y promoción de los derechos fundamentales que inciden en la dignidad humana y su libre desarrollo, aunque en Grecia hay algunas quiebras.

En el aspecto colectivo de ese Derecho se camina, en líneas generales, hacia una separación que en algunos Estados ya se ha logra-

${ }^{10}$ Artículo 13.2 y artículo 3 de la Constitución de 1975, reformada en 2008. Para los derechos individuales: artículos. 4, 5.1, 5.2, 13.1, 13.2 (primer inciso) y 7.2 del mismo texto.

${ }^{11}$ Las sentencias más relevantes al respecto han sido: Sentencia de 25 de mayo de 1993 Kokkinakis contra Grecia, y Sentencia 24 de febrero de 1998 Larissis contra Grecia. En http://biblioteca.uam.es/derecho/documentos/docencia/eclesia/ caso_LARISSIS.doc - 175.OKB - Bibliotecas. http://biblioteca.uam.es/derecho/documentos/docencial eclesialcaso_KOKKINAKIS.DOC - 118.5KB - Bibliotecas. 
do. Hay, entonces, una clara tendencia de futuro hacia la autonomía jurídica de las iglesias con respecto de los Estados. Sin embargo, no hay neutralidad, con lo que la laicidad no se desarrolla plenamente. Siguen existiendo estatutos jurídicos especiales y privilegiados para las iglesias que fueron nacionales, en detrimento de las confesiones minoritarias que solamente son reconocidas como personas jurídicas privadas. No obstante, la evolución de la sociedad y, sobre todo la inserción en ella de la inmigración va introduciendo, poco a poco, el acceso a un derecho especial algo más favorable para estos colectivos.

\section{II.1.B.b) Modelos de Estado Laico}

Las Constituciones de los diez países restantes de este primer grupo responden, en sentido amplio, a la categoría del Estado Laico, que en una consideración teórica se caracteriza por la neutralidad del Estado hacia las confesiones religiosas, la separación entre ambos, y la posibilidad de cooperación con las confesiones, con el fin de lograr la plena realización del derecho de libertad de conciencia de los individuos, objetivo fundamental de este tipo de Estado.

Sin embargo, es preciso señalar que en bastantes de ellos, se desvirtúan, algunos de estos principios.

Todos los Estados reconocen plenamente los derechos de igualdad y de libertad de conciencia en su aspecto individual, así como el derecho de autonomía jurídica de las confesiones religiosas, cosa que no ocurría en los modelos de Iglesia de Estado. Las diferencias entre ellos se establecen, una vez más, en el derecho colectivo de esta libertad, esto es, en la consideración jurídica de los colectivos religiosos, pues en la mayor parte de los Estados teóricamente laicos existen regulaciones privilegiadas para determinadas confesiones religiosas.

Un tratamiento igualitario sólo se produce en Francia, único país laico en sentido estricto (República laica, a tenor del art. 2 de la Constitución de 1958), donde las confesiones religiosas carecen de un derecho especial favorable; quedan sometidas al derecho común del Estado, al ser considerado el principio de igualdad como garantía de la libertad de conciencia; y no existen relaciones de cooperación con las confesiones, excepto en Alsacia, Lorena y Mosela, donde por razones históricas continúa vigente el Concordato Napoleónico de 1904, pues cuando se promulgó la Ley de Separación entre la Iglesia Estado de 1905, estos territorios se encontraban bajo soberanía 
alemana. El Concordato de Napoleón establece un sistema de cultos reconocidos, lo que supone la retribución con cargo al Estado de los ministros de culto católicos, protestantes y judíos. (Para un detenido examen del sistema francés: Barbier, 1995: 23-172).

El creciente cambio en la realidad social fruto de la inmigración, con fuertes implicaciones religiosas, provocó en 2003 la creación de una Comisión de reflexión sobre la aplicación del principio de laicidad en Francia. Resultado de ello ha sido el Informe Stasi, de 11 de diciembre de 2003, que insta a defender una laicidad que sea intransigente con la aplicación de los principios de la República y respetuosa con todas las confesiones. La laicidad, según el informe, reposa sobre tres valores: libertad de conciencia, igualdad de todas las confesiones y neutralidad del poder político. Esta idea ya estaba presente en la Ley de 12 de junio de 2001, sobre Prevención y represión de los movimientos sectarios que atenten contra los derechos del hombre y las libertades fundamentales, (ver comentario en Felix Ballesta, 2001: 491-532) y se ha desarrollado en otra Ley de 15 de marzo de 2004 que prohíbe en la escuela pública los signos religiosos ostensibles, y en la reciente Ley de 11 de octubre de 2010 que veta la ocultación del rostro en los espacios públicos: artículo 1.1 "Dans les écoles, les collèges et les lycées publics, le port de signes ou tenues par les quels les élèves manifestent ostensiblement une appartenance religieuse est interdit» (ver análisis realizado por Pérez Álvarez, 2012).

Hay otros cinco Estados donde se puede hablar de una laicidad en sentido amplio. Sus textos constitucionales responden a un modelo laico, pero la realidad social, en muchos aspectos, no se adecua a la Constitución. Distinguiré aquí dos grupos: Holanda e Irlanda, de un lado, y España, Italia y Portugal de otro.

Podría parecer, en una primera apreciación, que Holanda e Irlanda se aproximan más a la laicidad plena que los otros tres, pues no subvencionan con carácter general a ninguna confesión y no han suscrito acuerdos de cooperación. Las Constituciones de ambos países recogen, además, la autonomía jurídica propia de todas las confesiones religiosas ${ }^{12}$, que tienen un carácter de personas jurídico privadas.

No obstante, la realidad es muy distinta. En Irlanda la religión católica domina absolutamente en el plano sociológico y tiene en sus manos gran parte de la enseñanza, al no existir casi escuelas

${ }^{12}$ Artículo 6.1 de la Constitución de Holanda de 17 de febrero de 1983, última revisión de 2002 y artículos 44.2.5, 2.2 y 2.1 de la Constitución de Irlanda de 29 de diciembre de 1934, última revisión de junio de 2004. 
públicas. Lo mismo ocurre con los hospitales. Esta realidad influye en el Estado y se traduce en un evidente trato de favor para esta confesión (ver Casey, 1997: 149-171). En Holanda ocurre lo mismo con la iglesia católica y la calvinista, que pueden crear sus propios organismos políticos, sociales y culturales de orientación confesional, con ayudas especiales del Estado (Barbier,1995: 183). Pero, en todo caso, es importante reseñar que el derecho holandés tiene una de las regulaciones más progresistas en materia de libertad de conciencia individual (matrimonio homosexual, adopción por parejas homosexuales, eutanasia, etc.) aunque, en septiembre de 2011, el Gobierno ha aprobado un Proyecto de Ley que prohíbe el burka en espacios públicos, si bien, la norma ha de ser aún ratificada por las Cámaras legislativas (ver García Ruíz 2010: 195-221).

España, Italia y Portugal tienen como principios constitucionales comunes: el personalismo, la libertad de conciencia, la igualdad en la libertad, el pluralismo, la laicidad del Estado y la cooperación ${ }^{13}$, aunque este último principio no aparece recogido de forma expresa en la Constitución portuguesa, que guarda absoluto silencio en relación a este tema. Sobre la base de estos principios, las iglesias están separadas del Estado y tienen una autonomía jurídica plena, con el límite lógico del orden público constitucional.

Sin embargo, los tres países proceden de Estados confesionales y es innegable la existencia en ellos de algunas reminiscencias de confesionalidad. Pero, parten de una diferencia importante con respecto de Holanda e Irlanda: sus sociedades están más secularizadas y esta secularización va en aumento, lo que facilita notablemente la evolución futura hacia la laicidad plena. Esta secularización trasciende, incluso, a la regulación constitucional. Las tres tienen situaciones análogas, con una mayoría sociológica católica. Pero, de hecho, un importante porcentaje de ella, más claramente en España, no practica la religión, ni contribuye a su mantenimiento público (ver Pérez Agote, 2009: I, 375-398).

Se podría hablar, entonces, en estos tres países de una secularización más individual y menos social, entendida como el proceso por el cual las creencias y las prácticas religiosas de los individuos van disminuyendo, al igual que el poder de la religión para influir en el comportamiento concreto de las personas, sin que ello implique la desaparición de la identidad religiosa como referente cultural, que

${ }^{13}$ Artículos 1, 9.2, 10, 14 y 16 de la Constitución española de 1978; artículos 3, 7, 8, 19 y 20 de la Constitución italiana de 1947, última reforma de 2007, y artículos 1, 9, 13 y 41 de la Constitución Portuguesa de 2 de abril de 1976, última revisión de 2005. 
sigue teniendo peso en el ámbito social (ver Canas, 1996: 261-281 y Ferrari, 1996: 176-194).

La anterior confesionalidad produce, aún hoy, algunos problemas. Así, en España perviven ciertos privilegios para la iglesia católica, regulados en los Acuerdos suscritos con la Santa Sede en 1979, con algunos contenidos, en concreto, enseñanza de la religión católica y financiación de esta misma iglesia, que solo son compatibles con la Constitución desde la óptica de su carácter transitorio, o de un desarrollo normativo adecuado, ya que sino podrían violar principios constitucionales. No hay que olvidar que en un sistema democrático de libertades el reconocimiento y disfrute de los derechos fundamentales de individuos y grupos es obligado, y está garantizado para todos en condiciones de igualdad por el bloque constitucional, con lo que no es necesaria garantía suplementaria alguna (Suárez Pertierra, 2012: 123).

Los acuerdos suscritos con otras confesiones ${ }^{14}$, nacidos para desarrollar el derecho de libertad religiosa, se han ido convirtiendo, poco a poco, en normas privilegiarías, y una parte importante de los grupos confesionales no se pueden beneficiar de este régimen pacticio (ver Fernández-Coronado, 2009: 679-698). Por otra parte, todas las confesiones inscritas son asociaciones de derecho especial (un detenido análisis se encuentra en Pelayo, 2007: 229-389), con base en la Ley Orgánica de Libertad Religiosa de 5 de julio de1980, al margen de que hayan firmado o no pactos con el Estado.

Portugal evoluciona de un modo similar. La reciente reforma del Concordato suscrito con la Santa Sede en 1941, ha consolidado la laicidad del sistema portugués, superando uno de sus principales residuos de confesionalidad, como era el tratamiento del matrimonio canónico (ver Corral y Santos, 2004: 499-523). Además, ambos Estados han regulado el matrimonio homosexual ${ }^{15}$, y la nueva Ley de Libertad Religiosa portuguesa de 22 de junio de 2001 avanza notablemente en la igualdad y protección jurídica de las confesiones religiosas. Todo ello hace pensar en la voluntad de estos dos países de romper definitivamente con un pasado caracterizado por regímenes autoritarios de larga duración y escasa protección de los derechos humanos (López Guerra, 1996: 19).

${ }^{14}$ Con la Federación de Entidades Religiosas Evangélicas de España, La Federación de Comunidades Israelitas y la Comisión Islámica de España de 10 de noviembre de 1992 (BOE de 12 de noviembre).

${ }^{15}$ Respectivamente, Ley española de 3 de julio de 2005, y Ley portuguesa de 31 de mayo de 2010 sobre matrimonio entre personas del mismo sexo. 
En Italia, por el contrario, perdura una mayor influencia de la iglesia católica en la legislación estatal, quizás por el delicado equilibrio que ha de sostener con el Estado de la Ciudad del Vaticano.

La Constitución italiana en sus artículos 7 y 8 obliga a la cooperación mediante acuerdos (bilateralidad), lo cual, a parte de suponer, en todo caso, un privilegio constitucional para las confesiones susceptibles de firmarlos, establece un régimen privilegiado para la Iglesia católica respecto de las demás confesiones y puede poner en peligro la independencia y soberanía del Estado (ver Tozzi, 1994: 223-239).

Por último, tanto en España, como en Portugal e Italia, los grupos religiosos que no cumplen con los requisitos legales de confesión religiosa, se someten al Derecho común del Estado.

El resto de los Estados de la Unión Europea, teóricamente laicos, tienen, a mi juicio, una clara tendencia hacia la pluriconfesionalidad, que implica la existencia de una valoración social de lo religioso por la utilidad que representa para la consecución de los propios objetivos estatales.

De este modo, aunque la libertad de conciencia individual se reconoce en toda su amplitud, en el plano colectivo existe una evidente discriminación en relación con la posición jurídica de las distintas confesiones, recogida en algún caso en el propio texto constitucional $^{16}$ y se produce una importante cooperación entre el Estado y las confesiones de mayor relevancia social, adquirida por razones históricas culturales, jurídicas etc. En este sentido, Alemania, Austria y Luxemburgo tienen suscritos Concordatos con la iglesia católica ${ }^{17}$, los Estados Federales de la República Alemana han establecido también numerosos convenios con las iglesias más significativas, y Austria, junto al Concordato, ha regulado mediante leyes las relaciones del Estado con las confesiones de mayor relevancia social ${ }^{18}$.

${ }^{16}$ Artículo 137.5 y 6 de la Constitución de Weimar de 1919, que forma parte de la Ley Fundamental de la República Federal de Alemania de 23 de mayo de 1949; artículo 15 de la Ley Fundamental del Estado de Austria de 1929, StGG, última revisión de 2009; y artículo 22 en relación al 119 de la Constitución de Luxemburgo de 1868, última revisión de 2009.

${ }^{17}$ En Alemania el Concordato del III Reich de 1933; en Austria también un Concordato suscrito con la República austríaca en 1933, complementado posteriormente por varios convenios adicionales, y en Luxemburgo el Concordato Napoleónico de 1801, suscrito cuando la mayor parte de Luxemburgo era territorio francés, cuya vigencia actual es dudosa. Todos estos Concordatos tienen naturaleza jurídica internacional.

${ }^{18}$ Un detallado análisis de esta normativa se puede ver en la sección de Crónica 
Pero, además, en Alemania, Luxemburgo y Austria las iglesias de mayor presencia social e histórica, tienen la categoría de corporaciones de derecho público, lo que les permite participar de las estructuras del Estado con importantes contenidos, como el de percibir impuestos, en el caso de Alemania y Austria, o ser financiadas con cargo a los presupuestos estatales, como es el caso de Luxemburgo y Bélgica. Las confesiones minoritarias se someten, sin más, al derecho común (un detenido análisis de estos sistemas se encuentra en: Zabalza, 1986: Robbers. 2001: 643-668. Torres, 2006. Barbier, 1995).

De este modo, el concepto de iglesias privilegiadas cobra en estos países mayor relieve que en los demás Estados laicos aunque, paradójicamente en dos de ellos, Alemania y Bélgica, existe una equiparación jurídica a nivel constitucional de las asociaciones filosóficas con las confesiones religiosas reconocidas. Tal consideración la adquieren en el Derecho alemán las asociaciones que se dediquen al cultivo en común de una ideología, weltanschauung, a tenor del art. 137.7 de la Constitución de Weimar. En el derecho belga la equiparación se adquiere indirectamente por vía financiera. El art. 181 de la Constitución, reformado en 1993, señala que Las retribuciones y pensiones de los delegados de las organizaciones reconocidas por la ley, que ofrezcan asistencia moral de acuerdo con una concepción filosófica no confesional, correrán a cargo del Estado y se consignarán anualmente en los Presupuestos los fondos necesarios para atenderlas. Este hecho no regulado en ninguna otra Constitución, supone, sin duda, un importante respaldo al contenido del derecho de libertad de conciencia en su significación más amplia.

Por lo demás, Bélgica admite desde 2003 el matrimonio homosexual y la adopción por personas del mismo sexo y desde 2007 reconoce jurídicamente la transexualidad ${ }^{19}$. No obstante, también ha prohibido desde julio de 2011 el uso del burka en espacios públicos ${ }^{20}$.

Como conclusión al análisis realizado, se puede decir que en los Estados de este grupo encuadrados constitucionalmente en la categoría de Estados laicos existe una plena garantía del derecho individual de libertad de conciencia, pero en el aspecto colectivo, no se puede hablar de neutralidad en sentido estricto. Hay una o varias confesiones religiosas que gozan de un mejor derecho con respecto

Legislativa de la Revista Laicidad y Libertades, Escritos Jurídicos desde el n. ${ }^{\circ} 0$ al 11.

${ }^{19}$ Ley de 13 de febrero de 2003, Ley de 18 de mayo de 2006 y Ley de 10 de mayo de 2007.

${ }^{20}$ Ley de 23 de julio de 2011 sobre prohibición del burka en espacios públicos. Es el segundo país que establece esta prohibición, después de Francia. 
de los demás colectivos confesionales, ya sea por la existencia en su legislación de una valoración de lo religioso como bien social, o porque la implantación sociológica de una o varias religiones da lugar a una especial cooperación por parte del Estado.

Este derecho favorable a menudo va más allá de la laicidad positiva y deriva en privilegio. Cuando esto ocurre, la laicidad tiende hacia la pluriconfesionalidad y la diferencia con los sistemas de Iglesia de Estado se diluye en buena medida. Esta situación, además, implica una discriminación para las confesiones sin relevancia históricopolítica en el Estado, y para las minorías.

Finalmente, llama también la atención que en algunos de estos Estados, curiosamente en los más progresistas en materia de derechos individuales, han prohibido o están en trance de prohibir el burka o los signos religiosos ostensibles. La razón, a mi juicio, hay que buscarla en el impacto de la inmigración de países islámicos en esas sociedades, preocupadas por el aumento del terrorismo de ese signo, y en una cierta radicalización en algunos sectores que, amparados en el amplio respeto al pluralismo existente en estos Estados, han fomentado la aparición de ideologías favorecedoras de una política de control y rechazo, con el argumento de la puesta en peligro de la propia identidad cultural del Estado.

En conclusión, si comparamos el comportamiento de estos Estados, teóricamente laicos, con los Estados con modelo de Iglesia de Estado analizados anteriormente, vemos como las diferencias entre unos y otros no son demasiado significativas. La única diferencia realmente importante es la existencia de una autonomía jurídica propia de las confesiones religiosas en los modelos de laicidad, lo que no ocurre aún en las Iglesias de Estado. En este sentido se puede decir que las propias confesiones se van secularizando de la propia religión, para mostrarse como organización socio-jurídica que se independiza de la tutela jurídica estatal.

II.1.C. Los Estados de la ampliación de la Unión Europea de 2004-2006

El proceso de integración europea se vio afectado por la caídas del muro de Berlín en 1989, consecuencia del desmoronamiento de la Unión Soviética. Esta situación produjo como consecuencia la ampliación de la Unión Europea hacia Europa central y oriental. Estos nuevos Estados provienen, entonces, en su mayoría, excepto Malta y Chipre a los que me referiré más adelante, de países que se 
mantuvieron durante casi cincuenta años bajo el dominio soviético. Esta situación había producido la imposición a los mismos de unos principios ideológicos caracterizados en puridad por un monismo ideológico y jurídico, un dogmatismo excluyente, un colectivismo, una absoluta ausencia de personalismo y una diferente interpretación del derecho de libertad de conciencia, entendido como derecho a liberarse de las creencias religiosas. Hay que decir, sin embargo, que esta rigidez dogmática se fue relajando a lo largo del tiempo.

Estos principios se impusieron en los Estados que quedaron tras el denominado telón de acero, como consecuencia del acomodo de territorios realizados por los Aliados tras la Segunda Guerra Mundial. Sin embargo, tradicionalmente, estos países habían tenido una concepción ideológica diferente en esas materias. Como consecuencia de ello, cuando recuperan su independencia, se han movido entre las dos influencias ideológicas. En un primer momento, conservan una postura laica estricta, en consonancia con la influencia soviética, pero con el transcurso del tiempo han vuelto a resurgir en ellos buena parte de los principios ideológicos y religiosos que habían tenido históricamente.

En el aspecto político las Constituciones de estos Estados, como no podría ser de otro modo para formar parte de la Unión Europea ${ }^{21}$, recogen su carácter de Estados sociales y democráticos de Derecho, con plena garantía de los derechos y libertades fundamentales, y un status de Estados Laicos en sentido estricto.

Sin embargo, en relación al aspecto colectivo del derecho de libertad de conciencia, el desarrollo constitucional en los últimos diez años ha sacado a la luz unas Leyes de Libertad Religiosa con un tratamiento muy favorable a las confesiones tradicionales y numerosos Acuerdos de cooperación confesional, con un contenido que en muchos casos va más allá de lo exigido por la propia laicidad.

Por otra parte, cada vez es mayor el intervencionismo del Estado en la vida interna de las confesiones, aunque a rasgos generales continúa la separación con autonomía jurídica propia de las confesiones.

Estonia, Letonia y Lituania, se definen constitucionalmente como Estados sociales y democráticos de derecho, con plena libertad de

${ }^{21}$ La esencia de la integración estaba constituida por el cumplimiento de dos condiciones establecidas en el artículo 49, O del Tratado de la Unión Europea: pertenecer al continente europeo y respetar los principios en que se basa la Unión, enunciados en el apartado 1 del artículo 6 del Tratado y que se concretan en: democracia, respeto de los derechos humanos y las libertades fundamentales y Estado de Derecho 
conciencia, igualdad y no discriminación, y con expresa referencia a la protección de la dignidad humana ${ }^{22}$. Además, los tres se declaran Estados laicos con reconocimiento de la autonomía propia de las confesiones religiosas ${ }^{23}$. Sin embargo, en el aspecto colectivo del derecho de libertad religiosa, existe en los tres Estados un mejor reconocimiento jurídico a las llamadas confesiones religiosas tradicionales en materia de enseñanza y asistencia religiosa (ver Ringvee, 2006: 503-523, y Balodis, 2009: 1-12). Además, reciben financiación anual con cargo a los presupuestos de los Estados, por su contribución al desarrollo espiritual y cultural de los mismos ${ }^{24}$, y han firmado Acuerdos de cooperación con ellas. Las demás confesiones son personas jurídicas privadas. Hay, entonces una situación jurídica para determinadas confesiones que va más allá de lo que sería propio de un Estado laico y que es más acusada en Letonia y Lituania.

Chequia y Hungría también tiene una cierta tendencia hacia la pluriconfesionalidad, sobre todo la segunda. La Constitución Checa de 16 de diciembre de 1992 pone su fundamento en el respeto de los derechos y libertades del hombre y el ciudadano (art.1). A este texto constitucional se incorpora en la misma fecha, a tenor de su art. 3, la Carta de los Derechos y las Libertades Fundamentales, que considera a estos derechos como inembargables, inalienables, imprescriptibles e irrevocables (art. 1). La libertad de conciencia como derecho individual y colectivo se reconoce en los arts. 15 y 16 de la Carta en toda su amplitud, señalando, asimismo, que el Estado no puede estar vinculado a una ideología exclusiva o una fe religiosa particular (art. 2) y la autonomía jurídica propia de las confesiones (art. 15.2). Sin embargo, la cooperación es intensa.

${ }^{22}$ Constitución de 26 de junio de 1992, artículos 1, 9, 10, 12; artículos 91, 95 y 99 de la Constitución letona de 15 de octubre de 1998, reformada en 2007, y artículos 18, 21, 26 y 29 de la Constitución lituana. Recientemente, Estonia, la más secularizada de las tres Repúblicas Bálticas, ha promulgado una Ley de Igualdad de 1 de febrero de 2009, que en su artículo 1 establece la prohibición de discriminación de las personas por razón de religión creencias y orientación sexual.

${ }^{23}$ Artículo 40 de la Constitución de Estonia, que utiliza la fórmula de negar la existencia de una Iglesia de Estado No puede haber Iglesia de Estado.. El artículo 99 de la Constitución letona establece que La iglesia está separada del Estado, y el artículo 43 in fine de la Constitución lituana señala que El Estado no tiene religión oficial.

${ }^{24}$ Se trata de las religiones cristianas más importantes, en Estonia, a la que se unen, también, la islámica y judía en Letonia y Lituania: Ley de Iglesias y Congregaciones Religiosas de Estonia de 12 de febrero de 2002, reformada en 25 de febrero de 2004. Ley lituana de Comunidades y Asociaciones Religiosas de 4 de octubre de 1995, art. 5; Ley letona de organizaciones religiosas de 1995, art. 5. Esta legislación se puede consultar en Rodriguez, A, Pérez, S y Pelayo, J. D.(2004) «Crónica de los países del Este». En Laicidad y Libertades. Escritos Jurídicos, 4,II. 
La Ley sobre libertad de fe religiosa y sobre la posición de las iglesias y las sociedades religiosas de 1 de septiembre de 1991, modificada por Ley de 7 de enero de 2002, ofrece un importante elenco de colaboración estatal, como, por ejemplo, la financiación a las religiones más importantes con cargo a los Presupuestos del Estado (ver De Oto y Pribyl, 2008: 227-252). En concreto, el Estado checo garantiza la estabilidad económica de la Iglesia católica, y financia la enseñanza religiosa en centros públicos (ver Riobo, A., 2005: 398-402).

En parecidos términos, la Constitución húngara de 20 de agosto de 1949, reconoce los derechos fundamentales como inviolables e inalienables, así como la dignidad humana, la libertad de conciencia individual y colectiva, la separación entre iglesias y Estado y la autonomía jurídica propia de las confesiones. La Ley de Libertad de Conciencia y de Religión de 1990 establece los requisitos para ser confesión religiosa, y garantiza a las confesiones que contribuyan al funcionamiento de los servicios público un tratamiento similar a las instituciones estatales en el aspecto económico. Además, el Estado hasta 1998 financiaba directamente con cargo a los presupuestos a las iglesias tradicionales. Este sistema fue sustituido en por la una Ley sobre el Impuesto de la Renta de 1996 por un sistema de porcentaje impositivo, semejante al español o italiano. También hay ayudas en materia de asistencia religiosa ${ }^{25}$.

Se puede hablar, entonces, como en el caso de Chequia o de las Repúblicas Bálticas de una tendencia hacia la pluriconfesionalidad. Sin embargo, Hungría está en estos momentos experimentando una transformación en esta materia. La Ley sobre el Derecho a la Libertad de Conciencia y de Religión y sobre la situación de las Iglesias, confesiones religiosas y comunidades religiosas de 12 de julio de 2011, restringía los derechos y privilegios a las confesiones religiosas no históricas, posteriormente fue anulada por el Tribunal Constitucional en diciembre de 2011, pero fue reintroducida y aprobada con algunas modificaciones el 1 de enero de $2012^{26}$. Por su parte, la reciente Constitución aprobada por el Parlamento el 3 de enero de 2012, que posiblemente será modificada, plantea también problemas de restricción de derechos y

${ }^{25}$ Artículos 8, 54.1, 70 y 60 de la Constitución.

${ }^{26}$ Parece que no se trata de disminuir los derechos y privilegios de los que gozaban las iglesias, sino más bien de restringir el número de iglesias que los pueden recibir, mediante el endurecimiento de los requisitos para registrarse y un mayor control del Estado. Solo 14 de las 300 registradas, todas cristianas o judías, cumplen totalmente los nuevos requisitos que se exigen, el resto ha de volver a registrarse y ser aprobada por el Parlamento. La Ley puede consultarse: http://lapa.princeton. edu/hosteddocs/hungary/Act $\% 20 \mathrm{C} \% 20$ of $\% 202011 \% 20$ on $\% 20$ the $\% 20$ Right $\% 20$ to $\% 20$ Freedom $\% 20$ of $\% 20$ Conscience $\% 20$ and\%20Religion.pdf. 
libertades fundamentales, aunque, curiosamente, introduce la idea de religiosidad cristiana como inspiración de la vida pública, lo cual hace pensar en una cierta confesionalidad sociológica.

La Constitución de Polonia señala el respeto de los poderes públicos a la dignidad inherente e inviolable de la persona. Garantiza, asimismo, la igualdad y no discriminación y la libertad de creencias, y el derecho de las minorías étnicas y religiosas a proteger su identidad, motivado, sin duda, por la identidad judía ${ }^{27}$. En el art. 25 establece, además, la imparcialidad del Estado en materia de convicciones religiosas y filosóficas, la autonomía y mutua independencia entre el Estado y las confesiones religiosas, y la cooperación activa con estos colectivos.

No obstante, esta aparente laicidad choca con la realidad jurídica en esta materia. Polonia tiene un tratamiento de favor para la iglesia católica, mencionada de manera explícita en la Constitución, que establece el carácter de Tratado Internacional de los Acuerdos suscritos con ella. El Concordato con la Santa Sede de 1993, fija un estatuto jurídico privilegiado para esta confesión ${ }^{28}$. Además, existen leyes especiales que recogen los Acuerdos firmados con otras muchas confesiones religiosas de presencia significativa en la sociedad, en esencia con las confesiones cristianas y las comunidades judía y musulmana (ver Pietrzak, 1999: 481-490). Se puede concluir, entonces, que en materia de derecho colectivo de libertad de conciencia, la evolución del modelo polaco apunta a una desviación paulatina del modelo de laicidad señalado en la Constitución. Hay una cooperación muy activa con las confesiones religiosas, que va más allá de lo exigido por un Estado neutral y separado, y, además, esta cooperación no es igualitaria, destacando sobre las demás confesiones a la iglesia católica.

En un sentido similar, Eslovenia va dando pasos hacia un futuro favorable a la iglesia católica, mayoritaria en el Estado, si bien es cierto que, por el momento, es uno de los llamados Países del Este donde aún sigue estando presente con más fuerza la separación entre el Estado y las Confesiones. Así, la Constitución de 23 de diciembre de 1991, reformada el 27 de junio de 2006 establece la separación entre el Estado y las Iglesias y la tutela efectiva del derecho

${ }^{27}$ Artículos 30, 32, 35 y 53 Constitución de 16 de julio de 1997, puesta al día en 2009.

${ }^{28}$ Artículo 25.4 de la Constitución. El Concordato con la Santa Sede el 28 de julio de 1993, ratificado el 8 de enero de 1998, por su parte, establece efectos civiles al matrimonio canónico, financiación económica de la iglesia católica en la escuela pública, asistencia religiosa etc. Para un análisis del mismo. 
de libertad de conciencia ${ }^{29}$. Sin embargo, la Ley de Libertad Religiosa de 3 de marzo de 2007 ampara y extiende los derechos comunitarios de las confesiones religiosas, estableciendo una financiación en materia de asistencia religiosa, ayudas económicas, etc. Esta Ley ha sido recurrida ante el Tribunal Constitucional Esloveno, por el Consejo Nacional de la República de Eslovenia. El tribunal ha dictado sentencia en la que, tratando de dejar a salvo la separación entre el Estado y las iglesias, la igualdad entre todas las confesiones y la neutralidad del Estado, considera que todo ello es compatible con la cooperación confesional en el sentido que señalaba la citada Ley, siempre sobre la base de la igualdad religiosa ${ }^{30}$.

El Estado Esloveno, además, ha firmado Acuerdos con la Iglesia Católica $^{31}$, que han servido de modelo para Acuerdos posteriores con otras confesiones (ver Blaz I., 2009:12-34).

Rumania y Bulgaria se definen como Estados sociales y democráticos de derecho, con pleno respeto a los derechos de la persona y al libre desarrollo de la personalidad e igualdad y no discriminación por ningún motivo ${ }^{32}$. La constitución rumana reconoce que los cultos religiosos son autónomos del Estado, para señalar a continuación que tienen apoyo del Estado que les dará facilidades para la asistencia religiosa en centros públicos (artículo 29.5). Por su parte, la Ley de Libertad Religiosa de 27 de diciembre de 2006 muestra un claro intervencionismo estatal en la actividad de las confesiones religiosas (artículo 20 y siguientes) y se decanta hacia una clara pluriconfesionalidad, al establecer que el Estado contribuirá de modo significativo al pago de salarios de los ministros de los cultos reconocidos, principalmente la Iglesia Ortodoxa, mayoritaria en el Estado. Además, integra la enseñanza religiosa de estos cultos en el sistema

${ }^{29}$ Artículos. 5, 7, 21, 34, 35 y 41.

${ }^{30}$ Curiosamente, solo se muestra contrario a los requisitos para registrarse que señalaba la Ley (1.000 miembros y 10 años de antigüedad), por considerarlos restrictivos de la libertad religiosa, lo cual no obsta, sin embargo, para que la ley pueda conceder ciertos privilegios a las Iglesias que cumplan requisitos esenciales: Decisión $N .^{\circ}$ UI-92/07-23, 15 de abril 2010, Gaceta Oficial n. ${ }^{\circ}$ 46/2010.

31 También ha firmado Acuerdos con la Iglesia Evangélica (2002), la Pentecostal (2004), la Ortodoxa de Eslovenia (2004), la Comunidad Islámica (2007) y con los Budistas (2008). Estos Acuerdos toman como modelo el suscrito con la Santa Sede en 2001, que también había sido recurrido ante el Tribunal Supremo, que declaró su compatibilidad con la Constitución.

${ }^{32}$ Artículos 1, 4 y 6 de la Constitución Rumana de 8 de diciembre de 1991, actualizada en 2003, y artículos 1, 4, 6 de la Constitución de Bulgaria de 13 de julio de 1999, modificada en febrero de 2007. 
de enseñanza pública, y fomenta la representación religiosa en las instituciones públicas (ver Grigorita, 2007: 227-254).

Por el contrario, las religiones que no hubiesen podido adquirir ese estatus carecen de cooperación estatal, por lo que no hay un ejercicio real y efectivo del derecho de libertad de conciencia en su aspecto colectivo, sino más bien un tratamiento piramidal.

Bulgaria menciona a la iglesia ortodoxa, como religión tradicional en su Constitución (artículo 13.3), considerándola como religión tradicional. La Ley de Denominaciones Religiosas de 20 de diciembre de 2002, también menciona expresamente a dicha confesión, y reconoce su papel en Bulgaria aunque matiza a continuación que este hecho no puede servir de base para privilegios o ventajas legales (artículo 10.1, 2 y 3). Así mismo, el artículo 28 de la misma norma hace una previsión de financiación con cargo a los Presupuestos Generales del Estado para las confesiones registradas. Esta Ley, y especialmente su artículo 10.3 ha sido también objeto de recurso de constitucionalidad por un grupo de Diputados de la Asamblea Nacional, por entender que la consideración de la iglesia ortodoxa como religión tradicional, podría suponer una posición privilegiada y discriminatoria con respecto a las demás confesiones. El tribunal fallo en el sentido de la constitucionalidad de la norma, señalando que tal denominación no podrá servir de base para garantizar privilegios o ventajas legales (para un análisis: Torres, Hristov, Nokolov, Pterova, (2006): 533-598). No obstante, habrá que esperar el paso de tiempo para ver si esto realmente es así.

Por lo demás, se puede concluir que en ambos países el principio de igualdad regulado a nivel constitucional no está desarrollado adecuadamente, y existen discriminaciones de hecho por razón de orientación sexual y por pertenencia a la etnia gitana.

El resto de los países que integraron la ampliación de la Unión Europea, Eslovaquia, Malta y Chipre, tienen problemas de laicidad. Eslovaquia establece la protección de todos los derechos y libertades fundamentales reconocidas, sin ningún tipo de discriminación; garantiza la libertad religiosa individual y colectiva, garantizando a las confesiones, en este último aspecto, la enseñanza de la religión; y proclama que el Estado no esta unido a ninguna religión ni ideología $^{33}$. La Ley de Libertad Religiosa y estatuto jurídico de iglesias y sociedades religiosas de 1991 desarrolla la garantía de la libertad reli-

${ }^{33}$ Artículos 12.1 y 2, 24, de la Constitución de 1 de octubre de 1992, reformada en mayo 2006. 
giosa y establece los requisitos para el registro de las entidades religiosas, que da derecho a recibir subvenciones estatales. Los requisitos de inscripción son muy restrictivos, con lo que se limita el número de confesiones que pueden acceder a este régimen. Esta ley ha sido enmendada en agosto de 2007, restringiendo aún más los requisitos de inscripción, lo cual ha supuesto un mayor privilegio para las confesiones que alcancen ese estatus que, además, con esta ley reciben mayor financiación estatal, que será proporcional a su número de fieles $^{34}$.

La religión católica, mayoritaria en el país, tiende a menoscabar, poco a poco la neutralidad del Estado. Se ha firmado un Acuerdo Base con la Santa Sede el 24 de noviembre de 2000 donde se reconoce la eficacia jurídica del matrimonio canónico y de la jurisdicción canónica, la enseñanza religiosa católica en todos los centros educativos, y una previsión de financiación económica. Otro Acuerdo de 27 de noviembre de 2002 sobre asistencia religiosa a las Fuerzas Armadas y Cuerpos Armados, establece un Vicariato Castrense y financia esta asistencia, y otro de 2004 sobre enseñanza religiosa católica (ver Corral, Petschen, (2004: 427-484). También se ha elaborado un Acuerdo en 2007 sobre objeción de conciencia, donde se contempla la objeción de conciencia de los profesionales sanitarios al aborto, así como el compromiso del Estado de no imponer a los hospitales de la Iglesia la realización de interrupciones del embarazo. El Acuerdo no fue, finalmente aprobado por el Parlamento y produjo la caída del Gobierno en 2006. La pretensión de la iglesia católica es aprobarlo en un futuro, con el pretexto de proteger la libertad de conciencia en relación con otros valores universales como la vida, la dignidad humana, la familia o el matrimonio (ver Moravcikova y Riobo, 2010: 1-9). En mi opinión, no parece claro que con este planteamiento se esté protegiendo, ciertamente, la libertad de conciencia, sino más bien, la propia doctrina católica.

Eslovaquia también se han firmado Acuerdos con iglesias y sociedades religiosas no católicas en materia de asistencia religiosa (2005) y enseñanza y educación religiosa (2004), que toman como modelo a los acuerdos católicos.

Finalmente, los otros dos países que ingresaron en la Unión Europea en 2004, Malta y Chipre, no son laicos. La Constitución de Malta de 21 de septiembre de 1964, actualizada en 2007 en su artículo 2 señala que el

${ }^{34}$ Mediante una Ley de 12 de junio de 2007, se ha incrementado un $7 \%$ las subvenciónes a los cultos registrados: Informe 2008 sobre libertad religiosa en el mundo: 156-157. En http://www.libertadreligiosaenelmundo.com/Informe-Libertad-Religiosa.pdf. 
Estado profesa la religión católica y le confiere a esta religión el derecho y el deber de enseñar aquello que es lícito o ilícito, lo que implica una importante limitación al Estado democrático de derecho. Esta confesionalidad es compatible, a tenor del propio texto constitucional, con el respeto a los derechos fundamentales (artículos 1.1 y 32) y la libertad de conciencia y de culto individual (artículo 40). Sin embargo, el ordenamiento jurídico maltés desconoce en buena medida los principios de neutralidad y pluralismo religioso, lo cual dificulta el pleno ejercicio del derecho de libertad de conciencia.

En este sentido, Malta ha firmado cinco Acuerdos con la iglesia católica, dos sobre enseñanza, uno sobre cuestiones patrimoniales, otro sobre financiación de colegios católicos y otro sobre efectos civiles del matrimonio y reserva de jurisdicción en materia matrimonial (ver Corral, Petschen, 2004: 415-516). No hay, entonces, separación ni neutralidad y, en consecuencia, se produce un deficiente cumplimiento del pluralismo y la igualdad en la libertad.

Chipre es un caso especial, puesto que el Estado está integrado por dos comunidades: la griega y la turca. Este hecho condiciona la legislación estatal. La pertenencia a una u otra comunidad se determina por origen, lengua materna, cultura o pertenencia a la religión ortodoxa o musulmana. Los ciudadanos que no cumplan ninguno de estos criterios, podrán optar por una u otra en función de su religión ${ }^{35}$.

Existen dos Cámaras Legislativa con sus propias competencias, pero deberán de ejercerlas en el marco de la Constitución común. Ésta, regula la libertad de conciencia y religión, la igualdad y no discriminación por motivos religiosos (artículos 6 y 18) y a la vez mantiene los privilegios para las dos religiones tradicionales en materia de matrimonio (artículo 111), educación (artículo 20.1), y financiación (artículo 18.8). Se puede hablar, entonces, de un sistema de pluriconfesionalidad o, mejor aún, de biconfesionalidad. Las relaciones están fuertemente institucionalizadas, sin que se pueda hablar de neutralidad ni de separación, los dos presupuestos esenciales del Estado laico (ver Fernández-Coronado, 2002: 199-202).

Del análisis realizado se puede concluir que este grupo de Estados incorporados más recientemente a la Unión Europea, parece que va un paso por detrás de aquellos otros que he llamado tradicionales en materia de garantía y promoción del derecho de libertad de conciencia. Ello es debido a sus especiales características ideológicas

${ }^{35}$ Artículo 2 de la Constitución de Chipre de 1960, reformada en julio de 2006. 
durante casi cincuenta años, que determinaron un menor desarrollo de los derechos fundamentales de la persona, sobre todo de los derechos que inciden en el libre desarrollo de la personalidad. La ausencia de un pluralismo ideológico ha sido determinante, también, para la plena realización del derecho de libertad de conciencia y ha impedido la adecuada secularización de la sociedad, al contrario de lo que ocurrió en los Estados Europeos que he llamado tradicionales.

Consecuencia de todo ello ha sido que el fin del monismo ideológico sobre el que se asentaba la antigua Unión Soviética, provocó en un primer momento en estos Estados una especie de conflicto entre el laicismo impuesto y su identidad histórica. El resultado ha sido su vuelta a los esquemas ideológicos que habían sido tradicionales en ellos en el pasado, y que ya habían sido superados en buena medida en la que he llamado Europa tradicional, debido al mayor desarrollo de los derechos fundamentales.

Esta realidad se puede percibir, claramente, en el aspecto colectivo del derecho de libertad de conciencia, donde existe una mayor influencia de las religiones tradicionales en los objetivos de los Estados, con menoscabo de la neutralidad; un mayor intervencionismo estatal en la vida interna de las religiones; una separación más precaria y una importante discriminación de las minorías religiosas, a causa de la paulatina concentración de la cooperación estatal en las religiones tradicionales o históricas.

Esta misma valoración se puede aplicar en líneas generales a otros Estados Europeos que no forman parte de la Unión, como se verá a continuación.

\section{II.1.D. Estados Europeos no comunitarios}

Fuera de la Unión Europea, voy a hacer referencia a los países que por su peso en Europa o por su posible integración en la Unión en un espacio corto de tiempo, creo importante destacar.

En el primer caso se encuentra Rusia, cuyo peso no solo a nivel europeo, sino también mundial es evidente, aunque con alguna merma con respecto a la anterior Unión de Repúblicas Socialistas Soviéticas.

Desmantelada la Unión Soviética, la Constitución Rusa de 12 de diciembre de 1993 establece un Estado social de derecho, garante de los derechos fundamentales y la dignidad humana, con libertad de conciencia, y con prohibición de un monismo ideológico, como el 
que existía en el anterior sistema, así como de cualquier propaganda que incite a la discordia o a la superioridad religiosa, definiéndose como un Estado laico ${ }^{36}$. Antes de la promulgación de esta Constitución, una Ley de Libertad Religiosa de 1 de octubre de 1990, fruto de la Perestroika de Gorbachov, había proclamado ya la igualdad en la libertad religiosa de todos los cultos, haciendo depender la profesión o no de una religión de la voluntad del propio ciudadano.

Sin embargo, la presión de la iglesia ortodoxa, con un importante arraigo histórico en el Estado, produjo como consecuencia que, una vez promulgada la Constitución de 1993, se empezase a pensar en la reforma de la propia Ley. La causa para ello fue la proliferación de confesiones religiosas que se establecen en Rusia, debido a la permisividad de la citada norma. La reforma se llevó a cabo mediante la Ley de Libertad de Conciencia y de Asociaciones de 1 de octubre de $1997^{37}$ que retoma el control estatal sobre la religión, y choca con el contenido del propio texto constitucional. La Ley quiebra la igualdad religiosa, al considerar a la iglesia ortodoxa como fe tradicional de Rusia, y prohíbe las religiones que atenten contra las tradiciones históricas rusas, o que lleven menos de 15 años en el país, obligándolas a registrarse anualmente hasta que alcancen esa antigüedad (ver Martín Sánchez, 2004: 36-62).

Es la Ley de libertad religiosa más restrictiva del ámbito europeo y ha empezado a tener consecuencias. El Tribunal Europeo de los Derechos Humanos ha fallado contra el Estado ruso ordenando el reconocimiento jurídico de la Iglesia de la Cienciología (ver Pelayo, 2007: 1- 21) y de los Testigos Cristianos de Jehova ${ }^{38}$.

Finalmente, Croacia es el país más próximo en el tiempo a incorporarse a la Unión Europea. Ingresará el 1 de julio de 2013. Su Constitución de 22 de diciembre de 1990, revisada en 2001, establece un Estado social y democrático de Derecho (artículo 1), con igualdad y no discriminación de individuos grupos y minorías (artículos 1314). Prohíbe la incitación al odio religioso (artículo 39) y reconoce la libertad de conciencia plena (artículo 40) y la separación Estado Iglesia, así como la asistencia y ayuda del Estado a los colectivos religiosos (artículo 41).

${ }^{36}$ Artículos 2, 16, 17, 28, 13, y 14, respectivamente.

${ }^{37}$ Ver Preámbulo y artículos 4, 9, 11 y 27.

${ }^{38}$ La Sentencia de los Testigos de Jehova 10 de junio de 2010, por violación de los arts. 9, 11 y 6.1 del Convenio, se puede ver en Revista General de Derecho Canónico y Derecho Eclesiástico del Estado, 24 (octubre 2010). 
La libertad religiosa se desarrolla mediante una Ley de 2002 sobre la situación jurídica de las comunidades religiosas, donde se da un evidente trato de favor a las religiones inscritas, en materias como financiación, beneficios fiscales, enseñanza religiosa, etc. Hay, entonces, una valoración positiva de lo religioso con una tendencia más favorable a la iglesia católica, mayoritaria en el Estado, con la que se han firmado tres Acuerdos de cooperación ${ }^{39}$. En ellos se recoge un trato especial para esta confesión religiosa. Estos Acuerdos han servido de modelo para los firmados posteriormente con otras confesiones.

En conclusión, Croacia se sitúa en la línea de la cooperación activa con las confesiones más representativas, dentro de la tendencia hacia la pluriconfesionalidad, pero con un derecho más favorable para la iglesia católica, mayoritaria en el Estado, en parecidos términos a lo que ocurre en Eslovaquia.

Otros países europeos aún no cumplen los criterios de convergencia para entrar en la Unión, aunque se van estabilizando jurídica y socialmente, después de un largo período de turbulencias, y van adoptando estructuras cada vez más democráticas, propias de Estados de Derecho. Por poner un ejemplo, Serbia, ha legislado sobre igualdad y no discriminación por motivos, entre otros, de religión e identidad sexual, y ha promulgado una Ley sobre Comunidades Religiosas, al igual que Kosovo y, finalmente, Albania, uno de los países comunistas que habían sido más beligerantes contra la religión, ha establecido un Estado laico y como dato curioso ha firmado dos Acuerdos con la Santa Sede de reconocimiento mutuo (2002) y de Asuntos Económicos (2007), que contempla importantes exenciones fiscales ${ }^{40}$.

${ }^{39}$ Los tres son de 19 de diciembre de 1996: Acuerdo sobre asistencia religiosa a los fieles católicos miembros de la Fuerzas Armadas y de la Policía de la República de Croacia. Acuerdo sobre cuestiones jurídicas y Acuerdo sobre colaboración en materia de educación y cultura, actualizado el 23 de mayo de 2011. (www.vatican.va/roman_curia/../index_concordati-accordi_sp.htm). En líneas generales, el documento reconoce a la Iglesia católica el derecho de instituir escuelas de todo tipo y nivel y establece las respectivas obligaciones del Estado, incluidos los salarios de los profesores.

${ }^{40}$ Ley (n. ${ }^{\circ}$ 02/L-31 13 sobre Libertad Religiosa de Kosovo de 13 de julio de 2006; Ley sobre prohibición de discriminación de la República Serbia de 1 de enero de 2009; Ley sobre Iglesias y Comunidades Religiosas de 20 de abril de 2006, de la República Serbia; Acuerdo sobre Asuntos Económicos con la Iglesia católica de 3 de diciembre de 2007. En (Rodríguez Moya et al.) (2006, 2009, 2007, 2008). «Crónica de los Países del Este» En Laicidad y Libertades. Escritos Jurídicos, 6, II, 233-240 y 9, vol. II: 171; 7, II: 267; 8, II, 172 ss. 


\section{II.2. Ámbito del Derecho Comunitario}

Una vez analizado el Derecho de los Estados miembros en materia de libertad de conciencia, es preciso, ahora, pasar revista a la posición en esta materia del Derecho Comunitario.

La Unión Europea es un enorme intento de construcción política aún inacabado. Fue concebida en su Tratado constitutivo firmado en Roma en 1957 como una Unión Económica, aunque enraizada en una cultura común europea y en las culturas de los Estados miembros.

El Tratado de Maastricht de 1992, marcó el avance hacia la unidad política, señalando la obligación de la Unión de garantizar los derechos humanos y las libertades públicas, tomando como referentes de esa garantía el Convenio Europeo de los Derechos Humanos de 1950, y las tradiciones constitucionales comunes a los Estados miembros $^{41}$. Las confesiones religiosas no habían sido mencionadas en ningún momento en los Tratados fundacionales de la Unión Europea, ni se había planteado la posibilidad de establecer un diálogo con ellas.

Sin embargo, en la reunión intergubernamental de Bruselas de julio de 1997 para la reforma del Tratado de Maastricht, se pretendió la introducción en el Proyecto de reforma del Tratado de la Unión, de un artículo sobre la consideración jurídica de las iglesias en la Unión Europea. La iniciativa partió de un memorandum presentado por las iglesias alemanas ${ }^{42}$ y fue asumida por el Gobierno alemán que realizó la propuesta, con la única oposición de Francia y Bélgica. Esta iniciativa era fruto de la presión de los grandes grupos religiosos e ideológicos europeos y tenía dos pretensiones. En primer lugar, eludir la competencia de la Unión para legislar sobre las posiciones jurídicas de estos colectivos en las Constituciones de los Estados, al considerarlas como parte de la identidad del cada Estado. En segundo, que la futura reforma del Tratado de Maastricht respaldase jurídicamente en su derecho originario, esto es, en el articulado del Tratado, el reconocimiento expreso o el respeto de estos estatus jurídicos establecidos.

La propuesta no fue incluida en la parte dispositiva del Tratado de Amsterdam, pero si tuvo su eco en la parte declarativa. En efecto,

${ }^{41}$ Artículo F.2 del Tratado de Maastricht. En El Tratado de la Unión Europea (1992) Luxemburgo: Oficina de Publicaciones Oficiales de las Comunidades Europeas.

${ }^{42}$ Memorándum sur le statut jurídique des Églises et des communautés religieuses dans le dispositif conventionel de l'Unión européenne. Bonn-Hanovre, juni 1995. 
la Declaración n. ${ }^{\circ} 11$ del Acta final del Tratado, se refería al Estatuto de las iglesias y de las organizaciones no confesionales. Se trataba de una declaración sin valor jurídico, aunque de indudable importancia política. Establecía que «La Unión Europea respeta y no prejuzga el estatuto reconocido en virtud del derecho nacional, a las iglesias y las asociaciones o comunidades religiosas en los Estados miembros. La Unión Europea respeta, así mismo, el estatuto de las organizaciones filosóficas y no confesionales». Su función era declarar el respeto de la Unión Europea hacia las organizaciones religiosas e ideológicas de los Estados miembros, y no directamente la libertad de conciencia individual, aunque también hay que señalar que la Declaración equiparaba en tratamiento a las confesiones religiosas y a las asociaciones ideológicas, lo cual suponía un avance importante desde la perspectiva del derecho de libertad de conciencia en su dimensión colectiva.

Sin embargo, la ausencia de valor jurídico de la misma y su ubicación fuera del articulado del Tratado, revelaba las reticencias de la Unión para entrar a considerar en profundidad por el momento un tema de importantes consecuencias para la igual garantía del derecho de libertad de conciencia (Fernández-Coronado, 2002: 113-114).

Junto a este contenido el art. 6 del Tratado, modificado respecto del Tratado de Maastricht, introducía como cabecera un párrafo, que constituye una verdadera declaración de principios de la Unión Europea al señalar que La Unión se basa en los principios de libertad, democracia, respeto de los Derechos Humanos y de las Libertades Fundamentales y el Estado de Derecho, principios que son comunes a los Estados miembros.

El Tratado de Niza de 2001 no introdujo ninguna variedad en su parte dispositiva, aunque fue en la Conferencia Intergubernamental celebrada allí, donde se aprobó la Carta de los Derechos Fundamentales de la Unión Europea, aunque con un mero valor declarativo, que pasó a ser jurídico en el Tratado de Lisboa de 2009.

Con anterioridad, la Cumbre de Laeken de diciembre de 2001, se había propuesto como objetivo el dotar a la Unión Europea de una Constitución, que fue firmada en Roma el 29 de octubre de 2004 y tenía que ser ratificada por todos los Estados miembros, para entrar en vigor en 2006. Sin embargo, la negativa de Francia y de Holanda a esta ratificación, produjo como consecuencia la vuelta atrás del proceso, con la suspensión del refrendo por los Estados que aún no lo había realizado y el establecimiento de una nueva reforma del Tratado de la Unión. 
El proyecto de Constitución, en su artículo 7 señalaba en su primer párrafo la integración de la Carta de los Derechos Fundamentales en la Constitución con fuerza jurídica vinculante. En este sentido, el artículo establecía lo que podríamos denominar como un principio de integración, ya que descarta la incorporación material de la citada Carta a su contenido literal, para incluirla en la II Parte de la propia Constitución.

Ante el fracaso constitucional, en la Conferencia Intergubernamental de Lisboa de 23 de julio de 2007, se propuso un Proyecto de Tratado, que fue aprobado el 13 de diciembre de 2007 y entró en vigor, una vez ratificado por todos los Estados miembros el 1 de diciembre de 2009.

El vigente Tratado de Lisboa ofrece tres contenidos de relevancia esencial para el tema que nos ocupa: $1 .^{\circ}$ Valores de la Unión; $2 .^{\circ}$ Derechos fundamentales, y $3 .^{\circ}$ Posición jurídica de los grupos religiosos e ideológicos, en los ordenamientos jurídicos de los Estados.

1. ${ }^{\circ} \mathrm{El}$ Tratado establece como valores fundamentales: el respeto a la dignidad humana, la libertad, la democracia, el Estado de Derecho y el respeto a los derechos humanos, incluidos los derechos de las personas pertenecientes a minorías. Estos valores son considerados como comunes a los Estados miembros, en una sociedad caracterizada por el pluralismo, la tolerancia, la justicia, la solidaridad y la no discriminación, que constituyen una especie de valores sociales, que la Unión Europea debe promover como objetivo primordial, a tenor del propio texto constitucional $^{43}$. Este núcleo duro de valores se apoya directamente en las dos bases esenciales sobre las que se ha edificado la Unión Europea: la democracia como sistema político y el respeto a los derechos humanos, como credo. En consecuencia, bastaría un claro riesgo de violación grave de una de estas bases por un Estado miembro para iniciar un proceso de alerta y de sanción contra él.

2. ${ }^{\circ}$ En relación a los derechos fundamentales, el Tratado reconoce los derechos, libertades y principios enunciados en la Carta de los Derechos Fundamentales de la Unión Europea, a la que otorga el mismo valor jurídico que los Tratados (artículo 6.1).

La Carta reúne en un solo texto los derechos civiles, políticos, económicos y de sociedad enunciados hasta el momento en distintas fuentes internacionales, europeas y nacionales ${ }^{44}, \mathrm{y}$ constituye, sin

${ }^{43}$ Artículo 2 del Tratado de la Unión Europea. En Tratado de Lisboa. Textos Consolidados. Marcial Pons: 2010. 2. ${ }^{\text {a }}$ edición.

${ }^{44}$ Así lo proclamaron conjuntamente el Consejo, el Parlamento Europeo y la Co- 
duda, un importantísimo avance en el ámbito de la garantía y promoción del derecho de libertad de conciencia. Es, además, el primer texto sobre Derechos Fundamentales en el marco de la Unión ${ }^{45}$ ya que, uno de los grandes problemas existentes en el campo del Derecho comunitario era la ausencia de de una positivación de sus derechos fundamentales, pues la Unión Europea como tal entidad no había suscrito el Convenio Europeo de los Derechos Humanos de 1950.

Esta realidad dejaba fuera del ámbito de competencia del Derecho Comunitario a estos derechos que, además, carecían de garantía judicial, al quedar excluidos de la competencia del Tribunal de Justicia de las Comunidades Europeas, salvo lo relativo a la actuación de las instituciones en materias de competencia del Tratado (art. 46 del TUE).

La Carta tiene como eje central a la persona, su dignidad y los derechos que le son inherentes. Las novedades con respecto de éstos se centran en el reconocimiento expreso del derecho de objeción de conciencia, cuya regulación se remite a los Estados miembros, y la amplia enumeración de los motivos de prohibición de discriminación, entre los que cabe reseñar la religión, las convicciones, la pertenencia a una minoría y la identidad sexual, así como el respeto a la identidad cultural, religiosa y lingüística ${ }^{46}$.

También en materia de derechos fundamentales, el Tratado anuncia la adhesión de la Unión como entidad supranacional al Convenio Europeo de los Derechos Humanos de 1950, cosa a la que hasta entonces se había negado, y señala, por último, que los derechos fundamentales garantizados en dicho Convenio y los que son fruto de las tradiciones constitucionales comunes a los Estados miembros, forman parte del Derecho Comunitario como principios generales (ver Celador, 2011: 49-82).

3. ${ }^{\circ}$ Finalmente, en relación con el tema de las posiciones jurídicas de los grupos religiosos e ideológicos, señala que la Unión respetará y no prejuzgará el estatuto reconocido en el Derecho interno de los Estados miembros a estos grupos, y añade que, reconociendo su identidad y aportación específica, la Unión mantendrá un diálogo abierto, transparente y regular con ellos ${ }^{47}$.

misión en las conclusiones de la Conferencia Intergubernamental de Niza de 7, 8 y 9 de diciembre de 2000.

${ }^{45}$ El texto se puede consultar en Diario Oficial de las Comunidades Europeas. 18 de diciembre de 2000 (2000/C 364/01).

${ }^{46}$ Artículos 1, 10 capítulo III y artículos 52 y 53 .

${ }^{47}$ «1. La Unión respetará y no prejuzgara el estatuto reconocido en los Estados miembros, en virtud del Derecho interno, a las iglesias y las asociaciones o comuni- 


\section{CONVERGENCIA JURÍDICA DEL DERECHO DE LOS ESTADOS Y EL DERECHO COMUNITARIO EN MATERIA DE LIBERTAD DE CONCIENCIA}

En análisis realizado hasta esta momento, nos permite plantear la siguiente pregunta: $¿$ Es posible que el Derecho Comunitario ayude a avanzar en el camino hacia la laicidad plena a los Estados de la Unión Europea y, por ende, colabore en una armonización legislativa en materia de libertad de conciencia?

Pues bien, en el aspecto individual de este derecho resulta claro, según se ha visto, que del tratamiento de los valores y derechos fundamentales de la Unión en el Tratado en vigor, se deduce una importante tutela y promoción de los derechos inherentes a la dignidad humana. Se puede decir, entonces, que el Derecho Comunitario, no solo sigue la línea marcada por los Estados miembros sobre plena tutela y promoción del derecho de libertad de conciencia individual, sino que, además, ha avanzado en esta materia, al establecer, también, una especie de valores sociales comunes, constituidos por el pluralismo, la tolerancia, la justicia, la solidaridad y la no discriminación. No cabe duda de que la exigencia a los Estados de estos valores por parte del Tratado, facilita la secularización de la sociedad y puede influir en el avance hacia la neutralidad plena de los mismos.

Los problemas más importantes se producen, una vez más, con respecto de la posición jurídica de los colectivos religiosos e ideológicos en los Derechos de los Estados y su tratamiento por el Derecho Comunitario, según hemos visto en el artículo 17. 3. La pregunta es: ¿cómo se puede o se debe interpretar este tratamiento? De hecho, esta cuestión no ha sido pacífica, pues se ha alegado por algunos sectores que el artículo legitima el derecho de injerencia de las instituciones religiosas en el ámbito público y supone un atentado contra la separación, arriesgando la permanencia en el tiempo de los privilegios confesionales en los derechos de los Estados.

En mi opinión, son posibles dos lecturas del artículo. Una lectura en términos que podríamos llamar confesionales, considerando que lo que se pretende es, ciertamente, consolidar en el Tratado de la Unión los estatutos jurídicos nacionales privilegiados de algunas

dades religiosas. 2. La Unión respetará asimismo el estatuto reconocido en virtud del Derecho interno a las asociaciones filosóficas y no confesionales. 3. Reconociendo su identidad y su aportación específica, la Unión mantendrá un diálogo abierto, transparente y regular con dichas iglesias y organizaciones» (artículo 17 del Tratado de Funcionamiento de las Comunidades Europeas). 
confesiones, amparados en el respeto del principio de identidad de los Estados. Sin embargo, con esta interpretación la Unión Europea estaría limitando la competencia que se había asignado de legislar sobre derechos fundamentales. Ello podría implicar una contradicción entre los propios poderes de la Unión y arriesgaría continuas demandas ante el Tribunal Europeo de los Derechos Humanos, al constituir el artículo así interpretado, una excepción basada en factores religiosos e ideológicos del principio general de igual libertad y prohibición de discriminación, recogido en el Convenio de Roma de 1950, en la Carta de los Derechos Fundamentales de la Unión Europea y en el propio Tratado.

Es posible, también, otra lectura en términos que yo llamaría de neutralidad, que me parece más adecuada, pues no podemos olvidar que la Unión Europea es una construcción laica desde sus inicios. El artículo podría entenderse en esta línea, como una declaración de neutralidad con respecto de todas las confesiones e ideologías, mediante un pleno respeto al pluralismo.

La propia equiparación que el artículo hace en los dos primeros párrafos de las confesiones religiosas y las asociaciones filosóficas favorece esta interpretación, además de constituir un avance importante en materia de libertad de conciencia.

Considero que esta interpretación es la más acorde con las exigencias derivadas de la igual libertad de todos los ciudadanos de la Unión, que deberá de actuar como límite al que habrán de ajustarse los regímenes específicos de los grupos religiosos e ideológicos en los ordenamientos jurídicos de los Estados. De no ser así, la prohibición de cualquier forma de discriminación basada en motivos religiosos e ideológicos que el Tratado establece, quedaría vacía de contenido en determinados países.

En mi opinión, además, el carácter de grupos de convicción de las confesiones y cosmovisiones filosóficas puede legitimar la mención expresa al «diálogo abierto, transparente y regular con dichas iglesias y organizaciones», como señala el propio artículo. De este modo, se estaría enmarcando esta relación dentro del fomento del diálogo interreligioso y ecuménico entre comunidades de fe y de convicción para colaborar en la construcción europea.

Se trataría de que estos grupos participen en esa construcción, no como legisladores que tratan de influir en la legislación del Estado con sus creencias, con el fin de preservar privilegios, sino como colectivos a los que se les solicita informe previo, en condiciones de 
igualdad con otros grupos sociales relevantes, cuando se trate de materias que puedan incidir en el ejercicio de la libertad de conciencia de los ciudadanos.

Creo, por todo ello, que la construcción europea ha de hacerse sobre valores compartidos y no sobre afirmaciones de fe. Europa es una realidad diversa y plural en culturas, ideologías y políticas y, en mi opinión ésa es su gran fuerza. Lo que se debe de pretender, entonces, es integrar esa diversidad en un proyecto común, tanto de políticas, como de ideales. Como señalo en su día el Presidente SANTER, las relaciones entre la Unión y las estructuras europeas de las iglesias o asociaciones filosóficas deben consistir en la búsqueda de la utilización de conceptos nuevos en el contexto europeo y no en los que habitualmente se han venido utilizando en el contexto nacional.

\section{BIBLIOGRAFÍA}

BALODIS, R. (2009) «Las relaciones entre el Estado de Letonia y las organizaciones religiosas: de la realidad soviética al modelo de España e Italia». En Revista General de Derecho Canónico y Derecho Eclesiástico del Estado, 21: 1-12.

BARBIER, M.(1995) La Laicité. París: L’Harmattan.

BLAZ, I. (2009) «Concordatos entre la República de Eslovenia y la Santa Sede. De un modelo negativo a otro positivo de separación Iglesia Estado». En Revista General de Derecho Canónico y Derecho Eclesiástico del Estado, 21, págs. 1-36. En Revistas@iustel.com.

CANAS (1996), «Estado e Iglesia en Portugal». En G. Robbers, ed, Estado e Iglesia en la Unión Europea. Madrid: Universidad Complutense, págs. 261-281.

CASEY, J. «Estado e Iglesia en Irlanda». En G. Robbers, ed, Estado e Iglesia en la Unión Europea. Madrid: Universidad Complutense, págs. 149-171.

CELADOR, O. (2011) Libertad de conciencia y Europa. Un estudio sobre las tradiciones constitucionales comunes y el Convenio Europeo de los Derechos humanos. Madrid: Dykinson.

CORRAL, C. y PETSCHEN, S. (2004), Tratados internacionales de la Santa Sede con los Estados (1996-2003). Concordatos vigentes: IV. 427-484. Madrid: Universidad Pontificia de Comillas. 
DE OTO, A y PRIBYÎL, S. (2008) «Il riconoscimento di chiese e societá religiose nell' excecoslovacchia e nell'ordiena Republica Ceca». En Laicidad y libertades. Escritos jurídicos, 8, vol. I, págs. 227-252.

FELIX BALLESTA, M. A. (2001) «Comentario relativo a la Ley francesa n. ${ }^{\circ}$ 2001-504 de 12 de junio tendente a reforzar la prevención y la represión de los movimientos sectarios que atenten contra los derechos del hombre y las libertades fundamentales». En Laicidad y Libertades. Escritos Jurídicos, 1: 491-532.

FERNÁNDEZ-CORONADO, A. (2002) (Directora), El derecho de libertad de conciencia en el marco de la Unión Europea: Pluralismo y minorías, Madrid: Colex, 67-94 y bibliografía contenida en la nota 9.

FERNÁNDEZ-CORONADO, A. (2009), «Sentido de la cooperación en una sociedad multirreligiosa». En R. Navarro Valls, J. Mantecon y J. Martínez-Torrón, coordinadores, La libertad religiosa y su regulación legal, Madrid: Iustel, págs. 679-698.

FERRARI (1996) «Estado e Iglesia en Italia». En G. Robbers, ed., (1996) Estado e Iglesia en la Unión Europea, Madrid: Universidad Complutense, págs.173-194.

GARCÍA RUIZ, Y. (2010). «Iniciativas normativas para prohibir el uso del burka». En Laicidad y Libertades. Escritos Jurídicos, 10, II. págs. 195-221.

GRIGORITA, G. (2007) «La nouvelle loi roumaine sur la liberte religieuse et le regime general des cultes». En Laicidad y Libertades. Escritos Jurídicos, 7, II, págs. 227-254.

LÓPEZ GUERRA, L. (1996) «Introducción» a las Constituciones de los Estados de la Unión Europea. Madrid: Marcial Pons, págs. 11-30.

LLAMAZARES, D. (2011) Derecho de la libertad de conciencia. 2 vol. vol. I. Conciencia, tolerancia y laicidad. 4. ${ }^{\mathrm{a}}$ edicion, Pamplona: Civitas-Thonson, Reuter.

MAC CLEAN, D. (1996) «Estado e Iglesia en el Reino Unido». En G. Robbers, ed, citado, págs. 311-327.

MARTÍN SÁNCHEZ, I. (2004) «Libertad Religiosa en Rusia». En Revista general de Derecho Canónico y Derecho Eclesiástico del Estado, 4, págs. 17-62 Revistas@iustel.com.

MORAVCIKOVA, M. y RIOBO, A. (2010) «Regulación legal de la objeción de conciencia al aborto en la República Eslovaca». En R. Palomino Y S. Cañamares (Coordinadores), Objeción de concien- 
cia al aborto. En Revista General de Derecho Canónico y Derecho Eclesiástico del Estado, 23, págs. 1-9, en Revistas@iustel.com.

MURILLO, M., PARDO, P., RODRÍGUEZ, J. A. (2001) «Crónica legislativa de los países nórdicos». En Laicidad y Libertades. Escritos Jurídicos, 1: 559-598; y 8 vol. 2, págs. 187-188.

PELAYO, J.D. (2007) Las comunidades ideológicas y religiosas, la personalidad jurídica y la actividad registral: Madrid: Ministerio de Justicia., págs. 229-389.

PELAYO, J. D. (2007) «La legitimidad o ilegitimidad de la intervención administrativa en la formación de las comunidades religiosas (Comentario a la sentencia del TEDH. Asunto Iglesia de la Scienciology c. Rusia (demanda n. $\left.{ }^{\circ} 18147 / 02\right) »$. En Revista General de Derecho Europeo, 14, págs. 1-21. En Revistas@iustel.com.

PÉREZ AGOTE, A. (2009) «Religión, identidad política y Estado en España». En Laicidad y Libertades. Escritos Jurídicos, 9, vol. I, págs. 375-398.

PÉREZ ÁLVAREZ, S. (2012) «Retos de la gestión de la diversidad cultural en el ámbito educativo francés. El caso del velo y del pañuelo islámicos». En Regueiro, M. T. y Pérez, Alvarez, S. (Coordinadores) Gestión de la diversidad cultural en las sociedades contemporáneas. Valencia: Tirant lo Blanc (En prensa).

RINGVEE, R. (2006) «State and Religioos Associations in Estonia». En Laicidad y Libertades. Escritos Jurídicos. 6, I, págs. 503-523.

RIOBO, A. (2005) El derecho de libertad religiosa en la República Checa y en la República Eslovaca. Madrid: Dykinson.

ROBBERS, G. (2001) «Religious freedom in Germany». Brigham Young University Law Review (2): 643-668.

ROSELL, J. (1997) Los Acuerdos del Estado con las Iglesias en Alemania. Madrid: Centro de Estudios Políticos y Constitucionales.

SUÁREZ PERTIERRA, G. (2012) «La libertad religiosa, ideológica y de culto. Los principios informadores del Derecho Eclesiástico del Estado». En VV. AA. Derecho Eclesiástico del Estado. Valencia: Tirant lo Blanch, págs. 107-124.

TORRES, A. (2006) El derecho de libertad de conciencia en Austria. Madrid: Dykinson.

TORRES, A. HRISTOV, A. NOKOLOV, E. PTEROVA, I. (2006) «El derecho de libertad religiosa y de conciencia en la legislación 
búlgara postcomunista»: 533-598. En Laicidad y Libertades... 6, I, págs. 533-598.

TOZZI, V. (1994) «Grupi religiosi e i rapporti con lo Stato». En Il Diritto Ecclesiástico, vol. 105, págs. 223-239.

TRZECIAK, B. (1999) «Sentido, contenido y valoración del Concordato de Polonia». En Anuario de Derecho Eclesiástico del Estado, XV, págs. 481-492.

TRZECIAK, B. (1999) «La situation jiuridique des communautes religieuses en Pologne contemporaine». En European Journal for Church and State Research. VI, págs. 223-239.

ZABALZA, I. Las confesiones religiosas en el Derecho eclesiástico alemán. Barcelona 1986. 